\title{
Assessment of plasminogen activator inhibitor-1 in obese Egyptian children
}

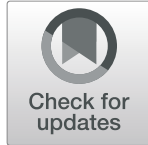

\author{
Marwa Farouk Mira 1* (D), Ghada Mohammad Anwar', Azza Mohamed Sarry EL-Din ${ }^{2}$ and \\ Safinaz Mohammed Megahed ${ }^{2}$
}

\begin{abstract}
Background: Plasminogen activator inhibitor-1 (PAI-1) is mainly produced in the liver and in the adipose tissue. Normal fibrin clearance mechanisms were found to be affected by high plasma PAI-1 levels and thus increases risk of thrombosis. The aim of the current study was to expound the childhood obesity effect on circulating PAl-1 and interpret the relation of PAI-1 to metabolic syndrome. This cross-sectional study was conducted on 43 obese children following in the Children Hospital and compared to 44 healthy sex- and age-matched controls. All recruited cohort are subjected to anthropometric measurements: weight, height, BMl, waist circumference, hip circumference, and skin fold thickness (biceps, triceps, and subscapular), and laboratory investigations in the form of lipid profile, fasting blood sugar, fasting insulin, insulin resistance estimated by HOMA-IR, and plasminogen activator inhibitor-1.

Results: The level of plasminogen activator inhibitor-1 in the obese group was significantly higher than that in the control group (47.98 \pm 17.42 vs. $28.00 \pm 11.35$ respectively). PAl-1 showed positive significant correlation to anthropometric measurements: BMI $(p=0.000)$, weight $(p=0.000)$, biceps skin fold thickness $(p=0.04)$, triceps skin fold thickness $(p=0.4)$, and subscapular skin fold thickness $(p=0.04)$. Also, a significant positive correlation was found between PAI-1 and systolic $(p=0.000)$ and diastolic blood pressure $(p=0.04)$. Positive correlations were found between PAl-1 and cholesterol $(p=0.000)$, triglycerides $(p=0.02), \operatorname{LDL}-c(p=0.000)$, insulin $(p=0.000)$, and HOMA-IR $(r=0.5, p=0.02)$.

Conclusion: Fat mass accumulation is related to high PAl-1 levels, which might in turn contribute to cardiovascular risk. Plasminogen Activator Inhibitor-1 is a good predictive test for metabolic syndrome in obese children.
\end{abstract}

Keywords: Children, Obesity, Plasminogen activator inhibitor-1, Metabolic syndrome

\section{Background}

It was found that thrombosis associated with obesity is mostly induced by inefficient fibrinolysis and chronic inflammation [1]. Plasmin is responsible for the instant breakage of any fibrin clot in a very important physiological process called fibrinolysis. Plasminogen activator inhibitor-1 (PAI-1) is the main regulator of fibrinolysis. It is a serine protease inhibitor which is secreted by the liver, adipose tissue, and vascular endothelium [2]. PAI-1 is responsible for the inhibition of the fibrin degradation process endogenously. It works through blockage of the

\footnotetext{
* Correspondence: marwa.mira@kasralainy.edu.eg

${ }^{1}$ Diabetes Endocrinology and Metabolism Pediatric Unit (DEMPU),

Department of Pediatrics, Faculty of Medicine, Cairo University, Kasralainy

street, Cairo 12411, Egypt

Full list of author information is available at the end of the article
}

action of tissue plasminogen activator and the urokinase-type activator, which consequently leads to the accumulation of fibrin in the interstitial tissues and the basement membranes [3-5]. Also, increased PAI-1 levels decrease normal fibrin degradation mechanisms and cause thrombosis [6]; it was believed that PAI-1 has a role in the development of the main components of the metabolic syndrome, and the increased PAI-1 levels are thought to be related positively to obesity and insulin resistance [7-9].

PAI-1 has been shown to be elevated in metabolic syndrome and generally is correlated with the number of components of metabolic syndrome present, such that the more severe the metabolic syndrome, the higher the PAI-1 levels [10, 11]. 


\section{Aim of the work}

The present study was done to investigate the impact of childhood obesity on circulating PAI-1 and its relationship to anthropometric measurements, insulin resistance, fasting blood sugar, and lipid profile. It also investigates the role of PAI-1 as a predictor for metabolic syndrome in the pediatric population.

\section{Methods}

The present work is a cross-sectional study conducted on 43 obese children recruited from Childrens' Hospital. Cases were compared to 44 healthy children, age and sex matched; they had normal BMI according to the Egyptian growth charts (2002) [12], with no clinical evidence or family history of obesity or metabolic syndrome. Patients recruited in the study had simple exogenous obesity with ages from 7 to 12 years. Obesity is defined as BMI at or above the 95th percentile for children of the same age and sex according to the Egyptian growth curves $[12,13]$. We meant by simple exogenous obesity, obesity not due to identified pathological cause, e.g., syndromic or endocrinological cause.

Patients excluded from the study were those with identified syndromes and chromosomal defects or endocrinal disorders causing obesity, those who were on medications like glucocorticoids or any affecting clotting profile, any diseases affecting fibrinolytic states (e.g., cardiovasular disease, hematological disease), and children with type 1 diabetes.

Patients recruited in the study were subjected to detailed history taking, duration of obesity, history of any present or past illness (renal, hepatic, endocrinal), history of drug intake, and family history of obesity, and hypertension, and thorough physical examination, the data of the systolic and diastolic blood pressure were plotted on blood pressure tables for children and adolescents of the fourth report on the diagnosis, evaluation, and treatment of high blood pressure in children as in National High Blood Pressure Education Program [14].

Weight was measured using Seca scale Balance. Height was measured using a stadiometer. Body mass index was calculated as weight in kilograms divided by the square of height in meters (wt $\left.(\mathrm{kg}) / \mathrm{Ht}(\mathrm{m})^{2}\right)$. Data obtained were plotted on the Egyptian Growth charts (2002) [12].

Waist circumference was measured at the end of gentle exhaling; a non-stretchable stain steal tape was held at a level midway between the lower rib margin and iliac crest all around the body in horizontal position parallel to the floor. Hip circumference is measured at the maximum protuberance of the buttock. Waist/hip ratio was then calculated [15].

Laboratory tests were done for all recruited subjects. Serum lipid profile \{total serum cholesterol (TC), serum triglycerides (TG), high-density lipoprotein (HDL)\} on a venous clotted sample type was centrifuged, and the serum was isolated by the device (Beckman, Synchron chemical system CK5). Assay of serum LDL cholesterol (LDL) was calculated from three primary measurements with the use of the Friedewald equation [16]. Fasting blood glucose was assayed using direct method by the device (Beckman, Synchron chemical system CK5) enzymatically, and fasting serum insulin was determined by immunoenzymometric assay using the Emmulite apparatus. Insulin resistance was estimated by using the homeostasis model assessment (HOMA) according to the following formula: HOMA = fasting serum insulin $(\mathrm{IU} / \mathrm{ml}) \times$ fasting serum glucose $(\mathrm{mg} / \mathrm{dL}) / 405$ (insulin resistance being defined as a HOMA index > 3.16). The greater the HOMA value, the greater the level of insulin resistance [17].

The current study used the following criteria for diagnosing metabolic syndrome (MetS). MetS was considered if three or more of the following criteria were present: abdominal obesity (WC $\geq 90$ th percentile for age and sex); fasting TG $\geq 110 \mathrm{mg} / \mathrm{dl} ; \mathrm{HDL} \leq 40 \mathrm{mg} / \mathrm{dl}$; systolic/diastolic BP $\geq 90$ th percentile for age, sex, and height; and fasting glucose $\geq 100 \mathrm{mg} / \mathrm{dl}$ [18-20].

Assessment of plasminogen activator inhibitor-1 was done by enzyme-linked immunoassay (ELISA); this assay recognizes recombinant and natural human PAI-1. No significant cross-reactivity or interference was observed. We calculated the mean value of the duplicate or triplicate readings for each standard and sample (from: Assaypro LLC, 30 Triad South Drive St. Charles, MO 63304.catalog No. EP11oo-1. Lot NO. o1491425).

\section{Statistical methodology}

Statistical analysis was performed using Statistical Package for Social Sciences $\left(\right.$ SPSS $\left.^{\oplus}\right)$ for Windows $^{\oplus}$ version 16.0. Measured data was described as mean and standard deviation (for parametric variables), number, and percentage (for categorical variables). Difference between the two groups was measured using unpaired Student's $t$ test (for parametric variables). Association between variables was assessed using Pearson's correlation coefficient (for parametric variables. ${ }^{*} p$ value $<0.05$ was considered significant.

\section{Results}

The study included 43 obese patients, and their mean age was $9.79 \pm 1.90$ ranged from 7 to 12 years; $53.4 \%$ $($ no. $=23)$ are males and $46.6 \%($ no. $=20)$ are females. Forty-four normal healthy age- and sex-matched control subjects were included in this study, and their mean age was $9.17 \pm 1.72$ ranged from 7 to 11 years; $52.4 \%($ no. $=22$ ) are males and $47.6 \%$ (no. $=21$ ) are females. Anthropometric and clinical data in the obese and control groups are illustrated in (Table 1). 
Table 1 Anthropometric, clinical, and laboratory data in the obese and control groups

\begin{tabular}{|c|c|c|c|}
\hline & Obese group (mean $\pm S D$ ) & Control group (mean \pm SD) & $p$ value \\
\hline Height (SDS) & $0.467 \pm 1.10$ & $-0.765 \pm 0.577$ & 0.042 \\
\hline Weight (SDS) & $3.16 \pm 1.52$ & $-0.0319 \pm 0.594$ & $0.000^{* *}$ \\
\hline $\mathrm{BMI}\left(\mathrm{kg} / \mathrm{m}^{2}\right)$ & $29.87 \pm 3.35$ & $18.22 \pm 1.87$ & $0.000^{* *}$ \\
\hline BMI (SDS) & $3.123 \pm 0.607$ & $-0.776 \pm 0.789$ & $0.000^{* *}$ \\
\hline Waist circumference (cm) & $88.38 \pm 8.28$ & $57.33 \pm 4.76$ & $0.000^{* *}$ \\
\hline Hip circumference $(\mathrm{cm})$ & $94.08 \pm 9.87$ & $68.86 \pm 7.33$ & $0.000^{* *}$ \\
\hline W/H ratio & $0.938 \pm 0.053$ & $0.830 \pm 0.047$ & $0.000^{* *}$ \\
\hline Biceps skin fold (SDS) & $1.9 \pm 1.72$ & $1.15 \pm 1.2$ & $0.000^{* *}$ \\
\hline Triceps skin fold (SDS) & $2 \pm 1.77$ & $0.80 \pm 1.08$ & $0.000^{* *}$ \\
\hline Subscapular skin fold (SDS) & $3 \pm 4.96$ & $0.91 \pm 1.06$ & $0.000^{* *}$ \\
\hline Systolic Bp (mmHg) & $115.28 \pm 9.06$ & $101.40 \pm 6.38$ & $0.000^{* *}$ \\
\hline Diastolic Bp (mmHg) & $77.79 \pm 11.56$ & $63.79 \pm 5.97$ & $0.000^{* *}$ \\
\hline Total cholesterol (mg/dl) & $168.40 \pm 28.44$ & $144.17 \pm 25.97$ & 0.000 \\
\hline Triglycerides (mg/dl) & $100.51 \pm 29.67$ & $57.60 \pm 15.02$ & 0.000 \\
\hline $\mathrm{HDL}-\mathrm{c}(\mathrm{mg} / \mathrm{dl})$ & $41.23 \pm 10.87$ & $43.191 \pm 11.037$ & 0.412 \\
\hline LDL-c (mg/dl) & $103.05 \pm 32.39$ & $89.74 \pm 20.74$ & 0.027 \\
\hline FBS $(\mathrm{mg} / \mathrm{dl})$ & $94.37 \pm 9.51$ & $87.69 \pm 9.94$ & 0.001 \\
\hline Insulin $(\mu \mathrm{IU} / \mathrm{ml})$ & $17.75 \pm 8.067$ & $7.78 \pm 2.58$ & 0.000 \\
\hline HOMA-IR & $4.14 \pm 1.94$ & $1.67 \pm 0.609$ & 0.000 \\
\hline PAl-1 (ng/dl) & $47.98 \pm 17.42$ & $28.00 \pm 11.35$ & 0.000 \\
\hline
\end{tabular}

W/H waist/hip ratio, $B M I$ body mass index, SDS standard deviation score, Bp blood pressure

${ }^{* *} p$ value highly significant $<0.01$

The comparison between obese and control groups regarding their lab results showed statistically significant difference between both groups in cholesterol, triglycerides, LDL-c, fasting blood sugar, fasting insulin, and HOMA-IR, while there was no statistically significant difference in HDL-c (Table 1).

Our study showed a highly significant positive correlation between PAI-1 and weight $(r=0.6, p=0.000)$, BMI $(r=0.6, p=0.000)$ (Fig. 1), and waist/hip ratio $(r=0.7$, $p=0.000)$ in the obese children. Also, there was statistically significant positive correlation between PAI-1 and the BMI SDS $(r=0.4, p=0.01)$, biceps skinfold thickness $(r=0.4, p=0.03)$, triceps skinfold thickness $(r=0.3, p=$ $0.04)$, and subscapular skinfold thickness $(r=0.3, p=$ 0.04). Regarding systolic and diastolic blood pressure, there was a significant positive correlation between PAI1 and systolic BP $(r=0.7, p=0.000)$ and diastolic BP $(r=0.3, p=0.04)$ (Table 2).

There is a positive significant correlation between PAI-1 and cholesterol $(r=0.5, p=0.000)$, triglycerides $(r=0.4$, $p=0.02)$, LDL-c $(r=0.6, p=0.000)$, insulin $(r=0.5, p=$ $0.000)$, and HOMA-IR $(r=0.5, p=0.02)$ (Table 2).

Twelve obese children (27.9\%) fulfilled the criteria for diagnosis of metabolic syndrome. WC is significantly higher in obese children with metabolic syndrome ( $p=$ 0.04) (Table 3).
PAI-1 was significantly higher in obese patients with MetS $(p=0.02)$. Obese patients with MetS showed significantly higher serum TG $(p=0.000)$ and fasting blood glucose $(p=0.000)$ (Table 3$)$.

\section{Discussion}

The current study shows that obese children have dysregulation of fibrinolytic system. The evidence is that the mean PAI-1 was significantly higher in obese children than the control subject $(47.98 \pm 17.42$ vs $28.00 \pm$ 11.35) $p$ value $<0.001$.

Plasminogen activators are responsible for the conversion of plasminogen to plasmin which accelerates fibrinolysis. These plasminogen activators are strongly and irreversibly inhibited by PAI-1. It was found that PAI-1 expression is markedly increased in visceral adipose tissue in obese individuals, and those with central adiposity have increased levels of PAI-1 [2].

There are several studies which observed positive correlations between PAI-1 and weight, weight standard deviation, height, BMI, BMI standard deviation, waist circumference, hip circumference, and waist to hip ratio in obese children [21-25].

Also, PAI-1 levels are observed to be high in patients with metabolic syndrome (MetS) [26]. Elevated levels of PAI-1 found in obese patients can be decreased by 


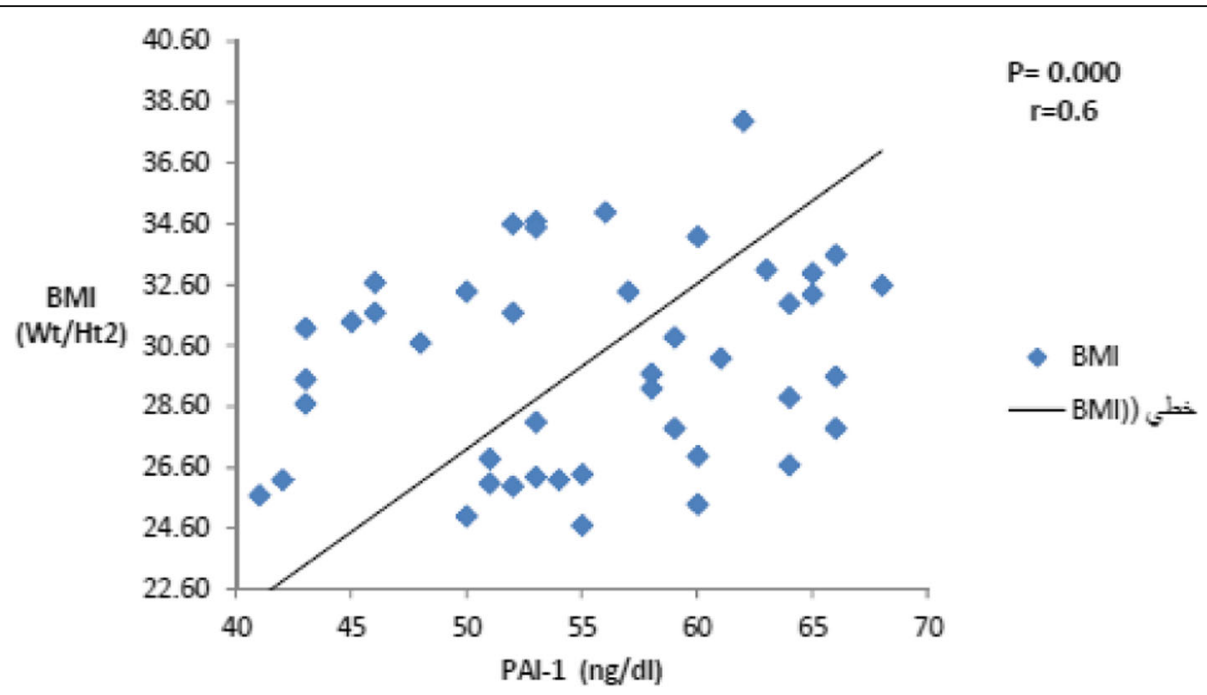

Fig. 1 Correlation between PAI-1 and BMI in obese group

Table 2 Correlation between PAl-1 and the anthropometric measures and blood pressure measurements and the laboratory data in obese group

\begin{tabular}{lll}
\hline PAl-1 in obese group & $R$ & $p$ \\
\hline Height (cm) & 0.2 & 0.3 \\
Height (SDS) & 0.1 & 0.4 \\
Weight (kg) & 0.6 & $0.000^{* *}$ \\
Weight (SDS) & 0.2 & 0.3 \\
BMl (kg/m $\left.{ }^{2}\right)$ & 0.6 & $0.000^{* *}$ \\
BMl (SDS) & 0.4 & $0.01^{*}$ \\
Waist circumference (cm) & 0.09 & 0.6 \\
Hip circumference (cm) & 0.1 & 0.4 \\
W/H ratio & 0.7 & $0.000^{* *}$ \\
Biceps skin fold (mm) & 0.4 & $0.03^{*}$ \\
Triceps skin fold (mm) & 0.3 & $0.04^{*}$ \\
Subscapular skin fold (mm) & 0.3 & $0.04^{*}$ \\
Systolic Bp (mmHg) & 0.7 & $0.000^{* *}$ \\
Diastolic Bp (mmHg) & 0.3 & $0.04^{*}$ \\
Cholesterol (mg/dl) & 0.5 & $0.000^{* *}$ \\
Triglycerides (mg/dl) & 0.4 & $0.02^{*}$ \\
HDL-c (mg/dl) & 0.3 & 0.08 \\
LDL-c (mg/dl) & 0.6 & $0.000^{* *}$ \\
FBS (mg/dl) & 0.1 & 0.4 \\
Insulin ( $\mu$ lU/ml) & 0.5 & $0.000^{* *}$ \\
HOMA-IR & 0.5 & \\
\hline Corretions bew & 9.5 & \\
\hline
\end{tabular}

Correlations between variables were done using Pearson's correlation coefficients for the parametric data and Spearman correlation coefficients for nonparametric data

${ }^{*} p$ value statistically significant $<0.05$

${ }^{* *} p$ value highly significant $<0.01$ changing lifestyle and following intensive programs for weight loss [27, 28].

In the current study, total cholesterol, triglycerides, LDL-c, fasting blood glucose, fasting insulin, and HOMA-IR were significantly increased in obese children in comparison with controls ( $p$ value $0.000,0.000,0.03$, $0.01,0.00$, and 0.00 respectively). These findings were consistent with the findings of others [22, 29-31].

Significant positive correlations between PAI-1 and fasting insulin concentrations may give us an idea about the role of insulin in stimulating PAI-1 synthesis in adipose tissue sites and how it is the cause of relating high levels of PAI-1 to fatness [32].

Also, Akanji et al. [31] found that PAI-1 is associated with insulin resistance found in obese subjects, and $\mathrm{Al}$ Daghri et al. [30] found that PAI-1 levels were correlated with HOMA-IR and fasting serum insulin. Many earlier reports had suggested associations between PAI-1 with insulin sensitivity, WC, and BMI in obese children and adolescents [33, 34]; this is in agreement with the current results as PAI-1 was found to be correlated with BMI, HOMA-IR, and insulin in obese children.

So we can conclude from the data above that the presence of insulin resistance found in obese children is a risk factor for atherothrombosis that increases the possibilities of cardiovascular disease later on. Despite the answer to the question why levels of PAI-1 are increased in obese individuals is not agreed upon yet, it has been found that the fat cell itself can produce PAI-1 that possibly explain the high levels found in obese patients [35]. Fatness does not directly enhance PAI-1 synthesis. But likely, it exaggerates the response of the fat cell to the inducers of PAI-1 [36].

In the present study, we found that obese children with MetS had significantly higher levels of PAI-1 than 
Table 3 Comparison between anthropometric and laboratory data in MetS and non-MetS obese patients

\begin{tabular}{|c|c|c|c|}
\hline Anthropometric data & MetS (no. $=12$ ) & Non-MetS (no. = 31) & $p$ value \\
\hline Height (SDS) & $0.523 \pm 0.971$ & $0.325 \pm 1.42$ & 0.6 \\
\hline Weight (SDS) & $3.41 \pm 1.70$ & $3.06 \pm 1.47$ & 0.5 \\
\hline $\mathrm{BMI}\left(\mathrm{kg} / \mathrm{m}^{2}\right)$ & $30.15 \pm 3.29$ & $29.15 \pm 3.55$ & 0.4 \\
\hline BMI (SDS) & $3.23 \pm 0.733$ & $3.08 \pm 0.560$ & 0.5 \\
\hline Waist circumference (cm) & $89.61 \pm 9.16$ & $85.21 \pm 4.21$ & $0.03^{*}$ \\
\hline Hip circumference $(\mathrm{cm})$ & $95.29 \pm 10.48$ & $90.96 \pm 7.58$ & 0.2 \\
\hline W/H ratio & $0.939 \pm 0.052$ & $0.934 \pm 0.054$ & 0.8 \\
\hline Biceps skin fold (mm) & $19.07 \pm 5.32$ & $18.75 \pm 2.99$ & 0.8 \\
\hline Triceps skin fold (mm) & $26.23 \pm 5.23$ & $25.00 \pm 3.28$ & 0.5 \\
\hline Subscapular skin fold (mm) & $25.25 \pm 3.67$ & $26.48 \pm 5.46$ & 0.5 \\
\hline Systolic Bp (mmHg) & $121.42 \pm 6.29$ & $112.90 \pm 8.92$ & $0.001^{*}$ \\
\hline Diastolic Bp (mmHg) & $82.92 \pm 12.15$ & $75.81 \pm 10.89$ & $0.04^{*}$ \\
\hline Total cholesterol (mg/dl) & $171.94 \pm 26.06$ & $159.25 \pm 33.32$ & 0.2 \\
\hline Triglycerides (mg/dl) & $125.83 \pm 32.86$ & $90.71 \pm 21.92$ & $0.000^{* *}$ \\
\hline $\mathrm{HDL}-\mathrm{c}(\mathrm{mg} / \mathrm{dl})$ & $40.08 \pm 13.53$ & $41.68 \pm 9.87$ & 0.8 \\
\hline LDL-c (mg/dl) & $89.75 \pm 43.91$ & $108.19 \pm 25.78$ & 0.2 \\
\hline FBS $(\mathrm{mg} / \mathrm{dl})$ & $103.08 \pm 4.36$ & $91.00 \pm 8.80$ & $0.000^{* *}$ \\
\hline Insulin $(\mu \mathrm{lU} / \mathrm{ml})$ & $19.31 \pm 7.40$ & $17.15 \pm 8.35$ & 0.4 \\
\hline HOMA-IR & $4.89 \pm 1.85$ & $3.85 \pm 1.93$ & 0.1 \\
\hline PAI-1 & $55.67 \pm 4.94$ & $49.84 \pm 4.52$ & 0.02 \\
\hline
\end{tabular}

Comparisons between groups were done using ANOVA test

${ }^{* *} p$ value highly significant $<0.01$

their counterparts without MetS $(p=0.02)$. This coincides with the results of Valle et al. [37] and GalliTsinopoulou et al. work [38], which showed that PAI-1 levels are directly associated with MetS among children and adolescents. The increased percentage of visceral fat tissue may be the linkage between MetS and elevated plasminogen activator inhibitor-1 (PAI-1). This might be explained by the metabolic derangements found in MetS such as hypertension, dyslipidemia, hyperinsulinemia, and hyperglycemia could all induce PAI-1 synthesis and release from different cell types [39]. However, Mantovani et al. [25] found that triglycerides, insulin, and HOMA-IR have no direct relation to fibrinolytic disorders in childhood and the pathogenesis explaining the elevation of PAI-1 levels in obese patients remains to be elucidated.

\section{Conclusions}

We concluded that PAI-1 is a good predictive test for metabolic syndrome in obese children and it is correlated significantly to other metabolic risk factors such as waist circumference, systolic blood pressure, and fasting blood pressure. Using multiple biomarkers for diagnosis and early detection of metabolic syndrome, and hence customized treatment and risk management, is an upcoming field with much room for research.

\section{Abbreviations \\ BMI: Body mass index; ELIZA: Enzyme-linked immunoassay; HDL: High density lipoproteins; HOMA-IR: Homeostasis model assessment; LDL: Low density lipoprotein; MetS: Metabolic syndrome; PAI-1: Plasminogen activator inhibitor-1; TC: Total cholesterol; TG: Triglycerides; WC: Waist circumference}

\section{Acknowledgements \\ Not applicable}

\section{Authors' contributions}

GA conceived of the study, participated in its design, and helped to draft the manuscript. AS participated in the study design and performed the immunoassays. SM participated in patient selection and data collection. MM participated in the study design and coordination and helped to draft the manuscript. All authors read and approved the manuscript.

\section{Funding}

Self-funding

\section{Availability of data and materials}

Not applicable

\section{Ethics approval and consent to participate}

Informed written consent was taken from all participants and their parents after full explanation of the purpose and nature of all procedures used, and the study was approved by Medical Research Ethics Committee, National Research Centre number: 13-069.

\section{Consent for publication}

Not applicable

Competing interests

The authors declare that they have no competing interests. 


\section{Author details}

'Diabetes Endocrinology and Metabolism Pediatric Unit (DEMPU), Department of Pediatrics, Faculty of Medicine, Cairo University, Kasralainy street, Cairo 12411, Egypt. ${ }^{2}$ Biological Anthropometry Department, Medical Research Division, National Research Center, Cairo, Egypt.

Received: 10 June 2019 Accepted: 29 November 2019

Published online: 06 January 2020

\section{References}

1. Tchernof A, Despres JP (2013) Pathophysiology of human visceral obesity: an update. Physiol Rev 93:359-404

2. Ouchi N, Parker JL, Lugus JJ, Walsh K (2011) Adipokines in inflammation and metabolic disease. Nat Rev Immunol 11:85-97

3. Dellas C, Loskutoff DJ (2005) Historical analysis of PAI-1 from its discovery to its potential role in cell motility and disease. Thromb Haemost 93:631-640

4. Kohler HP, Grant PJ (2000) Plasminogen-activator inhibitor type 1 and coronary artery disease. N Engl J Med 342:1792-1801

5. Lijnen HR (2005) Pleiotropic functions of plasminogen activator inhibitor-1. J Thromb Haemost 3:35-45

6. Kruithof EK, Baker MS, Bunn CL (1995) Biological and clinical aspects of plasminogen activator inhibitor type 2. Blood. 86:4007-4024

7. Juhan-Vague I, Alessi MC, Mavri A, Morange PE (2003) Plasminogen activator inhibitor-1, inflammation, obesity, insulin resistance and vascular risk. J Thromb Haemost 1:1575-1579

8. Loskutoff DJ, Samad F (1998) The adipocyte and hemostatic balance in obesity: studies of PAl-1. Arterioscler Thromb Vasc Biol 18:1-6

9. Ma L, Mao SL, Taylor KL, Kanjanabuch T, Guan Y, Zhang Y, Brown NJ, Swift LL, McGuinness OP, Wasserman DH et al (2004) Prevention of obesity and insulin resistance in mice lacking plasminogenactivator inhibitor 1. Diabetes. 53:336-346

10. Bilgili S, Celebiler AC, Dogan A, Karaca B (2008) Inverse relationship between adiponectin and plasminogen activator inhibitor-1 in metabolic syndrome patients. Endocr Regul 42:63-68

11. Srikanthan K, Feyh A, Visweshwar H, Shapiro Jl, Sodhi K (2016) Systematic review of metabolic syndrome biomarkers: a panel for early detection, management, and risk stratification in the West Virginian population. Int J Med Sci 13(1):25-38

12. Ghalli I, Salah N, Hussien F, Erfan M, El-Ruby M, Mazen I, Sabry M, Abd ElRazik M, Saad M, Hossney S, Ismaail, Abd El-Dayem S (2002) Egyptian growth curves for infants, children and adolescents. In: Satorio A, Buckler JMH, Marazzi N (eds) Crecerenelmondo. Ferring Publisher, Italy (2008)

13. CDC (2010) Defining childhood overweight and obesity. Centers for Disease Control and Prevention, Atlanta (http://www.cdc.gov/obesity/childhood/ defining.html 16th June).

14. National High Blood Pressure Education Program Working Group on High Blood Pressure in Children and Adolescents (2004) The fourth report on the diagnosis, evaluation, and treatment of high blood pressure in children and adolescents. Pediatrics 114:555-576

15. Seidell JC, Perusse L, Despres JP, Bouchard C (2001) Waist and hip circumferences have independent and opposite effects on cardiovascular disease risk factors: the Quebec Family Study. Am J Clin Nutr 74:315-321

16. Friedewald WT, Levy Rl, Fredrickson DS (1972) Estimation of the concentration of low density lipoprotein cholesterol in plasma, without use of the preparative ultracentrifuge. Clin Chem 18:499-502

17. Keskin M, Kendirci M, Kurtoglu S, Atabek M (2005) Homeostasis model assessment is more reliable than the fasting glucose/insulin ratio and quantitative insulin sensitivity check index for assessing insulin resistance among obese children and adolescents. Pediatrics 115(4):e500-e503

18. Cook S, Weitzman M, Auinger P, Nguyen M, Dietz WH (2003) Prevalence of a metabolic syndrome phenotype in adolescents: findings from the third national Health and Nutrition Examination Survey, 1988-1994. Arch Pediatr Adolesc Med 157:821-827

19. Reinehr T, de Sousa G, Toschke AM, Andler W (2007) Comparison of metabolic syndrome prevalence using eight different definitions: a critical approach. Arch Dis Child 92:1067-1072

20. Pedrosa C, Bruno O, Isabel A, Carlos SP, Maria DV, Flora C (2010) Obesity and metabolic syndrome in 7-9 years -old Portuguese school children. Diabetol Metab Syndr 2:4

21. Valle M, Gascon F, Martos R, VRuz FJ, Bermudo F, Ríos R, Cañete R (2000) Infantile obesity: a situation of atherothrombotic risk? Metabolism 49:672675
22. Dimitrijevic-Sreckovic V, Colak E, Djordjevic P, Gostiljac D, Sreckovic B, Popovic S, Canovic F, llic M, Obrenovic R, Vukcevic V, Nikolic D, Nisic T, Milic $G$, Pejcic G (2007) Prothrombogenic factors and reduced antioxidative defense in children and adolescents with pre-metabolic and metabolic syndrome. Clin Chem Lab Med 45:1140-1144

23. Steene-Johannessen J, Kolle E, Reseland JE, Anderssen SA, Andersen LB (2010) Waist circumference is related to low-grade inflammation in youth. Int J Pediatr Obes 5:313-319

24. Mauras N, Delgiorno C, Kollman C, Bird K, Morgan M, Sweeten S, Balagopal $P$, Damaso L (2010) Obesity without established comorbidities of the metabolic syndrome is associated with a proinflammatory and prothrombotic state, even before the onset of puberty in children. J Clin Endocrinol Metab 95:1060-1068

25. Mantovani A, Cassatella M, Costantini C, Jaillon S (2011) Neutrophils in the activation and regulation of innate and adaptive immunity. Nat Rev Immunol 11:519-531

26. Alessi MC, Nicaud V, Scroyen I, Lange C, Saut N, Fumeron F, Marre M, Lantieri O, Fontaine-Bisson B, Juhan-Vague I, Balkau B, Tregouet D, Morange P, the D.E.S.I.R. Study Group (2011) Association of vitronectin and plasminogen activator inhibitor-1 levels with the risk of metabolic syndrome and type 2 diabetes mellitus. Results from the D.E.S.I. R. prospective cohort. Thromb Haemost 106:416-422

27. Belalcazar LM, Ballantyne CM, Lang W, Haffner SM, Rushing J, Schwenke DC, Pi-Sunyer FX, Tracy RP (2011) Metabolic factors, adipose tissue, and plasminogen activator inhibitor-1 levels in type 2 diabetes: findings from the look AHEAD study. Arterioscler Thromb Vasc Biol 31:1689-1695

28. Singh A, Foster GD, Gunawardana J, McCoy TA, Nguyen T, Vander Veur S, Komaroff E, Rao AK (2012) Elevated circulating tissue factor procoagulant activity, factor VII, and plasminogen activator inhibitor-1 in childhood obesity: evidence of a procoagulant state. Br J Haematol 158:523-527

29. Estellés A, Dalmau J, Falcó C, Berbel O, Castelló R, España F, Aznar J (2001) Plasma PAl-1 levels in obese children: effect of weight loss and influence of PAl-1 promoter4G/5G genotype. Thromb Haemost 86:647-652

30. Al-Daghri NM, Al-Attas OS, Alokail MS, Alkharfy KM, Draz HM (2010) Relationship between resistin and aPAl-1 levels with insulin resistance in Saudi children. Pediatr Int 52:551-556

31. Akanji AO, Al-Isa AN, Thalib L (2011) Determinants of blood levels of some thrombogenic biomarkers in healthy Arab adolescent subjects. Clin Chem Lab Med 49:1681-1690

32. Taeye BD, Smith LH, Vaughan DE (2005) Plasminogen activatorinhibitor-1: a common denominator in obesity, diabetes and cardiovascular disease. Curr Opin Pharmacol 5:149-154

33. Amemiya S, Dobashi K, Urakami T, Sugihara S, Ohzeki T, Tajima N (2007) Metabolic syndrome in youths. Pediatr Diabetes 8:48-5454

34. Steene-Johannessen J, Kolle E, Anderssen SA, Andersen LB (2009) Cardiovascular disease risk factors in a population-based sample of Norwegian children and adolescents. Scand J Clin Lab Invest 69:380-386

35. Goldberg RB (2009) Cytokine and cytokine-like inflammation markers, endothelial dysfunction, and imbalanced coagulation in development of diabetes and its complications. J Clin Endocrinol Metab 94:3171-3182

36. Venugopal J, Hanashiro K, Nagamine Y (2007) Regulation of PAl-1gene expression during adipogenesis. J Cell Biochem 101:369-380

37. Valle M, Martos R, Gascon F et al (2005) Low-grade systemic inflammation hypoadiponectinemia and a high concentration of leptin are present in very young obese children, and correlate with metabolic syndrome. Diabetes Metab 31:55-62

38. Galli-Tsinopoulou A, Grammatikopoulou MG, Stylianou C, Emmanouilidou E, Kokka P (2010) Diabese youngsters have 3.7 more chances in developing metabolic syndrome compared with the obese. J Endocrinol Investig 33: 549-553

39. Tamakoshi $\mathrm{K}$, Yatsuya $\mathrm{H}$, Kondo $T$, Hori $Y$, Ishikawa M, Zhang $H$, Murata $\mathrm{C}$, OtsukaR ZS, Toyoshima H (2003) The metabolic syndrome is associated with elevated circulating C-reactive protein in healthy reference range, a systemic low-grade inflammatory state. Int J Obes Relat Metab Disord 27: 443-449

\section{Publisher's Note}

Springer Nature remains neutral with regard to jurisdictional claims in published maps and institutional affiliations. 